\title{
Production of Coal-Like Solid Fuel from Albizia Chinensis Sawdust via Wet Torrefaction Process
}

\author{
Herlian Eriska Putra ${ }^{*}$, Enri Damanhuri ${ }^{2}$, Kania Dewi' ${ }^{2}$, Ari Darmawan Pasek ${ }^{3}$ \\ 1 Research Unit for Clean Technology, Indonesian Institute of Sciences, Jalan Cisitu Sangkuriang, Bandung \\ 40135, Indonesia \\ 2 Faculty of Civil and Environmental Engineering, Institut Teknologi Bandung, Jalan Ganesa no. 10, Bandung \\ 40132, Indonesia \\ 3 Faculty of Mechanical and Aerospace Engineering, Institut Teknologi Bandung, Jalan Ganesa no. 10, Bandung \\ 40132, Indonesia \\ * Corresponding author's e-mail: erisbae@gmail.com
}

\begin{abstract}
Albizia Chinensis is a plant easily found in Indonesia and other South East Asian countries. The sawdust from this plant is a lignocellulosic waste that can be potentially upgraded for the fuel purposes. This research investigated the potential of upgrading sawdust into a coal-like solid for fuel by a wet torrefaction process. In this project, a $1 \mathrm{~L}$ torrefaction reactor with an electric heater was employed to perform the carbonization of the Albizia chinensis sawdust. Wet torrefaction was performed in batch at temperatures of $190-230^{\circ} \mathrm{C}$ with holding times of $20^{\circ} \mathrm{C}, 30$ and $60 \mathrm{~min}$. The solid to water ratios of 1:3, 1:5 and 1:10 were used. The results showed that the chemical and physical properties of sawdust and hydrochar varied as a function of reaction temperature, holding time and solid load. The results also suggested that wet torrefaction could increase the fixed carbon in sawdust while the ash content and volatile matter decreased. The high heating value of hydrochar was $24.55 \mathrm{MJ} / \mathrm{kg}$ higher than raw sawdust, $18 \mathrm{MJ} / \mathrm{kg}$. $\mathrm{CO}_{2}$ was predominantly detected in the gas phase, reaching the of $>90 \% \mathrm{CO}_{2}$. The liquid products were identified as sugar and organic acid compounds, which may be desirable feedstock for biochemical production.
\end{abstract}

Keywords: Albizia chinensis, hydrochar, sawdust, solid fuel, wet torrefaction

\section{INTRODUCTION}

Sengon (Albizia chinensis) is a species of legume in the Albizia genus, native to south and southeast Asia, from India to China and Indonesia [Heuzé et al., 2018]. The sengon tree is a versatile tree used for various purposes. The leaves are used for animal feed and the wood stem is widely used for various purposes as processed wood, especially for light construction. The large number of the sengon wood uses has increased the sawdust waste. Using the wood sawdust as an alternative source of energy biomass is attractive, especially in the countries that produce wood, so that no wood will be wasted. The sengon wood sawdust contains $49.40 \%$ cellulose, $24.10 \%$ hemicellulose and 26.50\% lignin [Martawijaya et al., 1989]. The amount of sawdust is abundant, easy to obtain and inexpensive because it is a byproduct of the wood processing industry.

Although the biomass waste is easily found in nature, using it for heat and power generation is quite difficult [Demirbas, 2005; Saidur et al., 2011]. In general, the biomass waste is very heterogenic and very difficult to transport and store [Shoksani and Fenton, 2006]. The biomass waste has a high moisture content and low energy density, meaning that using it directly for fuel is not suggested. Additionally, the non-combustible inorganic components in the biomass waste cause fouling and corrosion [Demirbas, 2003].

Along with the advance of technology, the public opinion about waste should be changed. The use of biomass waste for the refuse-derived 
fuel (RDF) also needs to be improved. RDF can be produced by crushing and dehydrating the waste biomass with a waste converter technology. In order to upgrade the biomass waste using an environmentally beneficial process, torrefaction can be an option [Prins et al., 2006; Chen and Kuo, 2010]. Torrefaction can produce a coal-like material that has better fuel characteristics compared to biomass.

Generally, this technology can be classified into two categories: dry and wet torrefaction. Dry torrefaction (DT) can be defined as the thermal conversion of biomass under oxygen-free conditions at temperatures within the range of $200-300^{\circ} \mathrm{C}$ and at atmospheric pressure [Chew and Doshi, 2011]. Wet torrefaction (WT), also referred to as hydrothermal carbonization (HTC) [Hoekman et al., 2011], is a thermochemical conversion technique which uses liquid water as a reaction medium for the conversion of wet biomass.

A wet torrefaction process comprises a series of chemical reactions in a water medium, the properties of which change markedly with temperature [Kruse and Damen, 2015]. In the WT processes, subcritical water, typically ranging from $180-350^{\circ} \mathrm{C}$, is used to heat feedstock [Lu et al., 2012], even though the carbonization reaction itself can occur at moderate temperatures of 180 $250^{\circ} \mathrm{C}$ [Mumme et al., 2011] at autogenous pressures in a closed vessel. The reactions that happen in a WT process are comprised of hydrolysis, aromatization, and decarboxylation. Compared to DT, WT can produce better solid fuel properties in a lower reaction time [Chen et al., 2012].

Although WT of biomass has recently received great attention, compared to the heterogenic biomass waste, the majority of researchers prefer using the biomass plants with high lignocellulose content. Lignocellulose comprises mainly lignin, cellulose and hemicellulose and is easy to handle with less effort to meet environmental requirements. Sawdust is a lignocellulosic waste that can be potentially upgraded for fuel purposes. Only a few studies tested the WT of pine sawdust [Reza, 2011; Zhang et al., 2017; Zheng et al., 2017]. However, no studies on WT of sawdust from a legume tree such as Albizia chinensis have been performed.

\section{MATERIAL AND METHODS}

Albizia chinensis sawdust (Fig. 1) was used for this study. It was obtained from a local sawmill in Padalarang, West Java, Indonesia. The size of the sawdust is less than $10 \mathrm{~mm}$. It was dried and stored in a sealed plastic container before being used.

WT of sawdust was processed in the $1 \mathrm{~L}$ batch stirred reactor. This reactor was also used in a previous study [Eriska et al, 2017]. The reactor, made from SS-304 stainless steel, had electrical heater and agitator (Fig. 2). In order to analyse the effect of process parameters on sawdust, the WT was investigated at different holding times $(0.5$ and 1 hour), biomass to water ratios $(\mathrm{B} / \mathrm{W})(0.1$, $0.2,0.33)$, and reaction temperatures $(190,210$, and $230^{\circ} \mathrm{C}$ ).

A $50 \mathrm{~g}$ sample of sawdust was loaded into the reactor. Then, deionized water at several $\mathrm{B} / \mathrm{W}$ ratios, was placed to reactor. The nitrogen gas was also flowed into the reactor in order to make an oxygen-free system. The reactor was set up at the desired temperature and held for 0.5 and 1

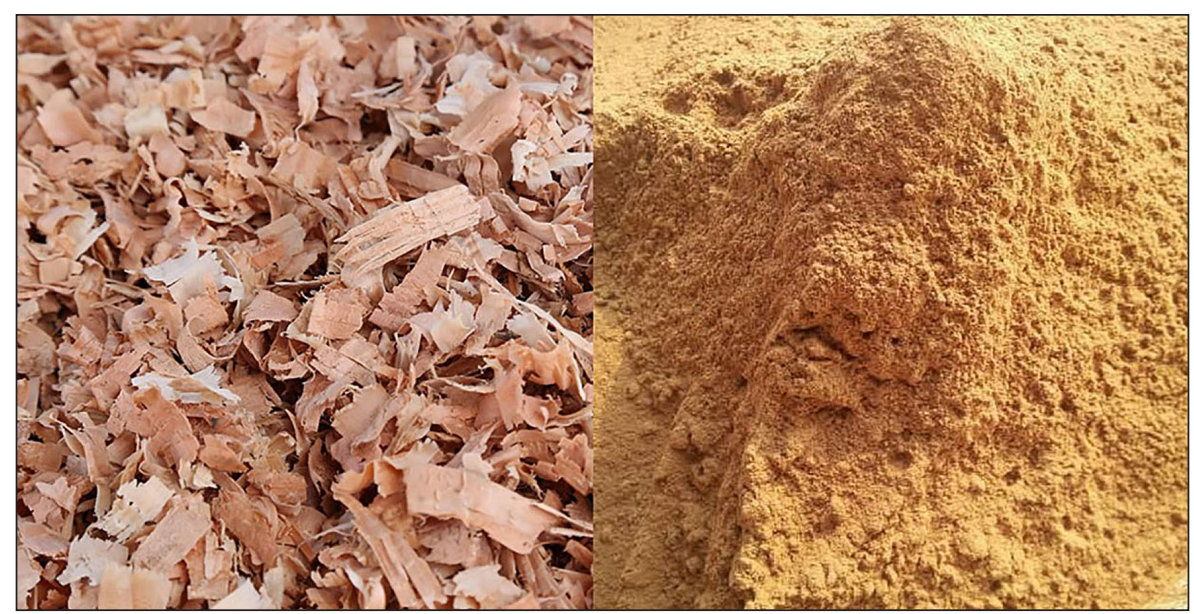

Figure 1. Albizia chinensis sawdust 


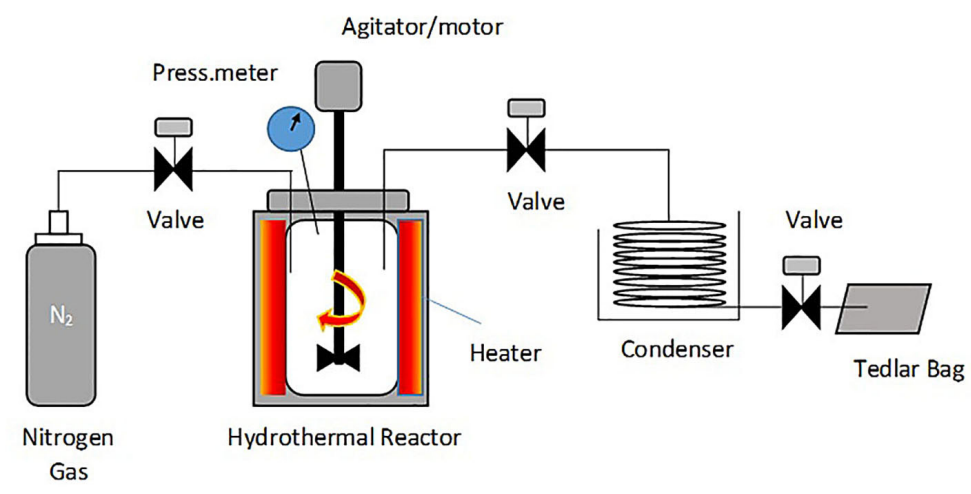

Figure 2. Wet torrefaction system

hour. When the process was completed, the inside temperature of the reactor was allowed to cool down. The valve was opened under a fume hood to release pressure and gases. Both liquid and solid products were separated using a filter paper $(2 \mu \mathrm{m})$. Solid fuel (hydrochar) was placed in a desiccator for around 24 hours before analysis. Both the gas and liquid composition were identified once, only for the process condition that showed the best result for energy.

The analysis of the ash content, volatile matter and fixed carbon (proximate) from solid product was performed using a Leco TGA-601. The sample was placed into the furnace, maintained at $103 \pm 2^{\circ} \mathrm{C}$ for 24 hours and then placed into a desiccator, containing silica gel, for cooling. According to ASTM-E871, a percentage moisture of sample was determined the difference between the initial and final weight. The percentage of ash was determined according to ASTM-E1755 where the dried samples were burned at $575^{\circ} \mathrm{C}$ for 5 hours in a furnace. The percentage of volatile matter was determined according to ASTM-E872 by firing sample at $950^{\circ} \mathrm{C}$ for 7 minutes. The percentage of fixed carbon was the remaining percentage reported after whole analysis was done.

Elementar Vario Macro was used to determine the ultimate analysis (carbon (C), hydrogen $(\mathrm{H})$, oxygen $(\mathrm{O})$, nitrogen $(\mathrm{N})$, sulphur $(\mathrm{S})$ ), while the high heating value (HHV) was measured using a bomb calorimeter. The liquid phase products were also analysed for the organic acids and sugar content. The organic acids were analysed and quantified by high-performance liquid chromatography (Shimadzu, Japan) with a UV-VIS detector. The gaseous product was identified using gas chromatography (column support 80/100 Chromosorb PAW, TCD detector). This analysis was supervised by the refinery unit laboratory in Indonesia. In this study, there were three parameters that were calculated by the formulas below.

$$
\begin{gathered}
\text { mass yield }= \\
=\frac{\text { mass of dried hydrochar }}{\text { mass of dried feedstock }} \times 100 \% \\
\text { energy densification }= \\
=\frac{H H V \text { hydrochar }}{H H V \text { feedstock }} \times 100 \% \\
\text { energy yield }= \\
=\text { mass yield } \times \text { energy dens.ratio }
\end{gathered}
$$

\section{RESULTS AND DISCUSSION}

\section{Effect of Process Condition}

Table 1 shows the experimental design that was completed in this study. Three different operating parameters were varied (holding time, biomass to water ratio and reaction temperature) to determine their effect on the calorific properties of sawdust. The results presented in Table 1 are mean values of duplicate experiments using statistical analysis (ANOVA, at 95\% confidence interval). These results show that the most significant parameters in controlling the properties of biomass were temperature and holding time. No significant effect was found for varying the biomass to water ratio. Similar results were also reported elsewhere; the use of biomass to water ratio had no significant effect of on the carbonization process of loblolly pine [Reza, 2011].

The Albizia sawdust itself contains $49.40 \%$ cellulose, $24.10 \%$ hemicellulose and $26.50 \%$ 
Table 1. Experimental design for feedstock and hydrochar

\begin{tabular}{|c|c|c|c|c|c|}
\hline \multirow{2}{*}{$\begin{array}{c}\text { xTemp } \\
\left({ }^{\circ} \mathrm{C}\right)\end{array}$} & \multirow{2}{*}{$\begin{array}{c}\text { Biomass } \\
\text { to water ratio } \\
(\mathrm{BWR})\end{array}$} & \multirow{2}{*}{$\begin{array}{l}\text { Time } \\
\text { (hour) }\end{array}$} & Mass yield & Energy yield & High heating value \\
\hline & & & $\%$ & $\%$ & $\mathrm{MJ} / \mathrm{kg}$ \\
\hline \multirow{6}{*}{190} & \multirow{2}{*}{0.33} & 0.5 & 68.11 & 79.08 & 19.165 \\
\hline & & 1 & 67.59 & 78.87 & 19.318 \\
\hline & \multirow{2}{*}{0.2} & 0.5 & 67.87 & 78.84 & 19.423 \\
\hline & & 1 & 66.43 & 78.67 & 19.695 \\
\hline & \multirow{2}{*}{0.1} & 0.5 & 66.22 & 77.92 & 19.803 \\
\hline & & 1 & 66.13 & 75.53 & 20.073 \\
\hline \multirow{6}{*}{210} & \multirow{2}{*}{0.33} & 0.5 & 66.21 & 77.56 & 19.583 \\
\hline & & 1 & 66.16 & 75.48 & 20.390 \\
\hline & \multirow{2}{*}{0.2} & 0.5 & 65.59 & 74.23 & 20.715 \\
\hline & & 1 & 64.75 & 71.87 & 21.672 \\
\hline & \multirow{2}{*}{0.1} & 0.5 & 65.34 & 71.36 & 21.838 \\
\hline & & 1 & 64.08 & 68.58 & 22.882 \\
\hline \multirow{6}{*}{230} & \multirow{2}{*}{0.33} & 0.5 & 64.36 & 70.22 & 22.187 \\
\hline & & 1 & 63.98 & 69.37 & 23.023 \\
\hline & \multirow{2}{*}{0.2} & 0.5 & 63.44 & 69.21 & 23.444 \\
\hline & & 1 & 61.89 & 69.73 & 24.082 \\
\hline & \multirow{2}{*}{0.1} & 0.5 & 62.37 & 69.07 & 23.905 \\
\hline & & 1 & 60.89 & 69.05 & 24.554 \\
\hline
\end{tabular}

lignin. In the WT process, the lignocellulose component, especially cellulose and hemicellulose, was decomposed to smaller molecular through hydrolysis. 90-99\% of the hemicellulose decomposed in the range $180-220^{\circ} \mathrm{C}$ and less than $15 \%$ of the lignin was decomposed below $250^{\circ} \mathrm{C}$ [Bobleter, 1994; Yuliansyah et al., 2010]. The results suggested that cellulose and hemicellulose were easier to decompose than lignin. It also explains the reason the calorific value of sawdust increased after treatment due to its fixed carbon increase. The results also showed that the mass yield slightly decreases with an increase in holding time and temperature. The black carbonaceous solid product which is produced from this process is hydrochar (Fig. 3).

Scanning electron microscope (SEM) images (Fig. 4) showed how sawdust had lost its structure during WT. The working pressure had spurred the removal of hemicellulose via degradation and depolymerisation reactions [Funke and Ziegler, 2010]. The process also improved the brittleness of product.

\section{Proximate and Ultimate Analysis of Hydrochar}

The ultimate analysis of raw sawdust and hydrochar were summarized in Table 2. The carbon content of hydrochar varies depending on the process conditions, so it was difficult to compare the carbon contents collected in recent study with former publications. The differences between process temperature, working pressure, holding time, reactor type, biomass to water ratio, type of water medium and catalyst were able to influence the result. In this study, the highest carbon content is $72.4 \%$ for the hydrochar produced at $230^{\circ} \mathrm{C}$, BWR 0.1 and $60 \mathrm{~min}$ holding time. As higher condition processes are used, the carbon content becomes higher. This trend is contrary to the hydrochar yield (Table 1).

The proximate analysis was the most general method used to determine the quality of solid fuels. It comprises an analysis of fixed carbon (FC), volatile matter (VM) and ash content (Ash), Fig. 5-7, respectively. FC was the ignitable residue once the volatile matter was completely burned. Generally, biomass has high VM and moisture content but low FC. Increasing the VM and FC contents via the WT process will lead to an increase in HHV. Figure 4 shows that the FC of sawdust was increased after the WT process.

Figure 6 shows that the VM content in the samples decreased during WT. As the temperature increase, some volatile matter was probably evaporated and released into the air thereby increasing the calorific value. The lower the amount of process water uses in process, the lower volatile matter content in the sample since a decrease in the biomass to water ratio reduces the 


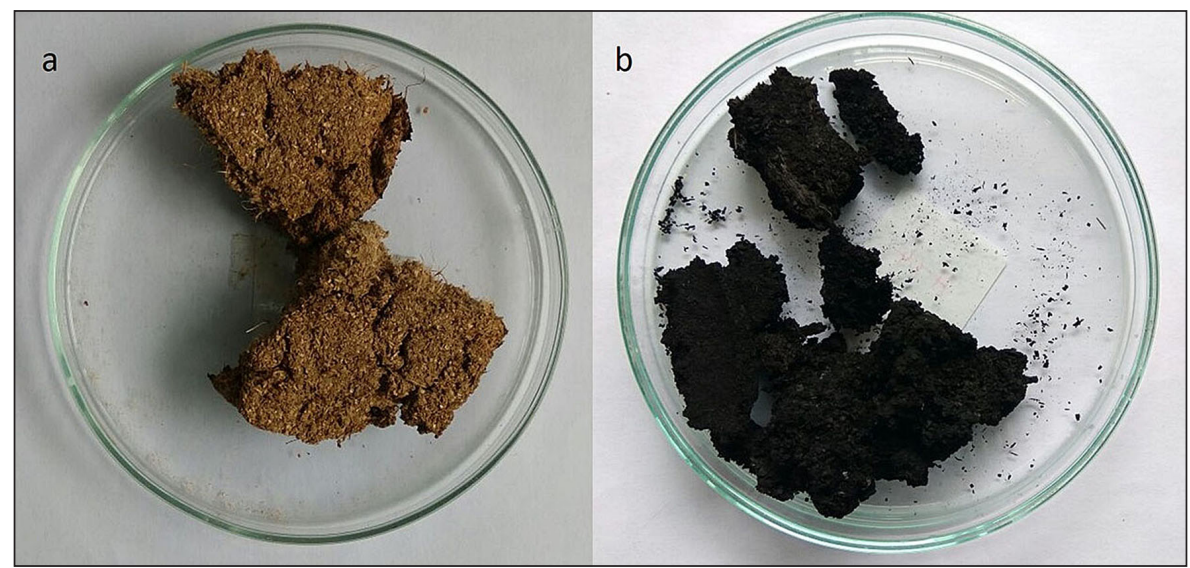

Figure 3. The visual image of (a) raw (b) hydrochar

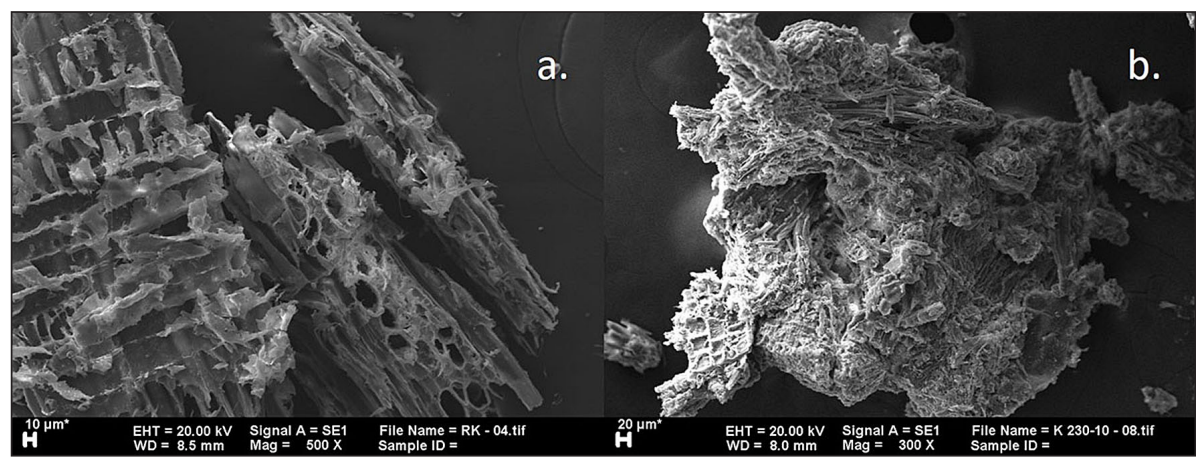

Figure 4. SEM images of sawdust: (a) raw (b) WT at $230^{\circ} \mathrm{C}$.

Table 2. Ultimate analysis of hydrochar

\begin{tabular}{|c|c|c|c|c|c|c|c|}
\hline \multirow{3}{*}{$\begin{array}{l}\text { Temp } \\
\left({ }^{\circ} \mathrm{C}\right)\end{array}$} & \multirow{3}{*}{$\begin{array}{c}\text { Biomass to water } \\
\text { ratio }(\mathrm{g} / \mathrm{ml})\end{array}$} & \multirow{3}{*}{$\begin{array}{l}\text { Time } \\
\text { (minute) }\end{array}$} & \multirow{2}{*}{ Moisture content } & \multicolumn{4}{|c|}{ Ultimate } \\
\hline & & & & C & $\mathrm{H}$ & $\mathrm{N}$ & $\mathrm{O}$ \\
\hline & & & $\%$ & $\%$ & $\%$ & $\%$ & $\%$ \\
\hline Raw & & & 14.9 & 52.5 & 6.0 & 0.2 & 42.3 \\
\hline \multirow{6}{*}{190} & \multirow{2}{*}{0.33} & 30 & 4.6 & 55.3 & 6.0 & 0.2 & 38.2 \\
\hline & & 60 & 5.3 & 59.9 & 5.9 & 0.2 & 33.6 \\
\hline & \multirow{2}{*}{0.2} & 30 & 4.8 & 57.3 & 6.0 & 0.2 & 37.4 \\
\hline & & 60 & 5.5 & 59.7 & 5.7 & 0.2 & 31.7 \\
\hline & \multirow{2}{*}{0.1} & 30 & 5.2 & 60.1 & 5.7 & 0.2 & 35.2 \\
\hline & & 60 & 5.7 & 62.5 & 5.7 & 0.2 & 30.8 \\
\hline \multirow{6}{*}{210} & \multirow{2}{*}{0.33} & 30 & 6.5 & 62.5 & 5.7 & 0.2 & 30.7 \\
\hline & & 60 & 6.9 & 68.7 & 5.6 & 0.2 & 24.9 \\
\hline & \multirow{2}{*}{0.2} & 30 & 6.8 & 64.7 & 5.6 & 0.2 & 28.5 \\
\hline & & 60 & 7.1 & 68.5 & 5.4 & 0.2 & 23.1 \\
\hline & \multirow{2}{*}{0.1} & 30 & 6.8 & 67.8 & 5.5 & 0.2 & 27.0 \\
\hline & & 60 & 7.3 & 69.6 & 5.4 & 0.1 & 22.1 \\
\hline \multirow{6}{*}{230} & \multirow{2}{*}{0.33} & 30 & 7.4 & 65.8 & 5.4 & 0.1 & 28.7 \\
\hline & & 60 & 7.7 & 69.6 & 5.3 & 0.1 & 24.0 \\
\hline & \multirow{2}{*}{0.2} & 30 & 7.8 & 67.4 & 5.2 & 0.1 & 26.1 \\
\hline & & 60 & 8.2 & 70.2 & 5.1 & 0.1 & 21.9 \\
\hline & \multirow{2}{*}{0.1} & 30 & 8.1 & 69.3 & 5.3 & 0.1 & 22.5 \\
\hline & & 60 & 8.6 & 72.4 & 5.1 & 0.1 & 21.9 \\
\hline
\end{tabular}


possibility interaction between the sample and reaction medium.

Figure 7 shows that the ash content increases after processing. This because the lignin and cellulose content from sawdust is dominant. Compared to hemicellulose, both lignin and cellulose have a tendency to decompose at temperatures higher than $200^{\circ} \mathrm{C}$. The determination of ash content in the WT process is necessary. The characteristics of ash performance a main role to upscale system design. Ash, inorganic residue left over after burning process, can cause slagging, fouling, and corrosion of reactor if not handled carefully.

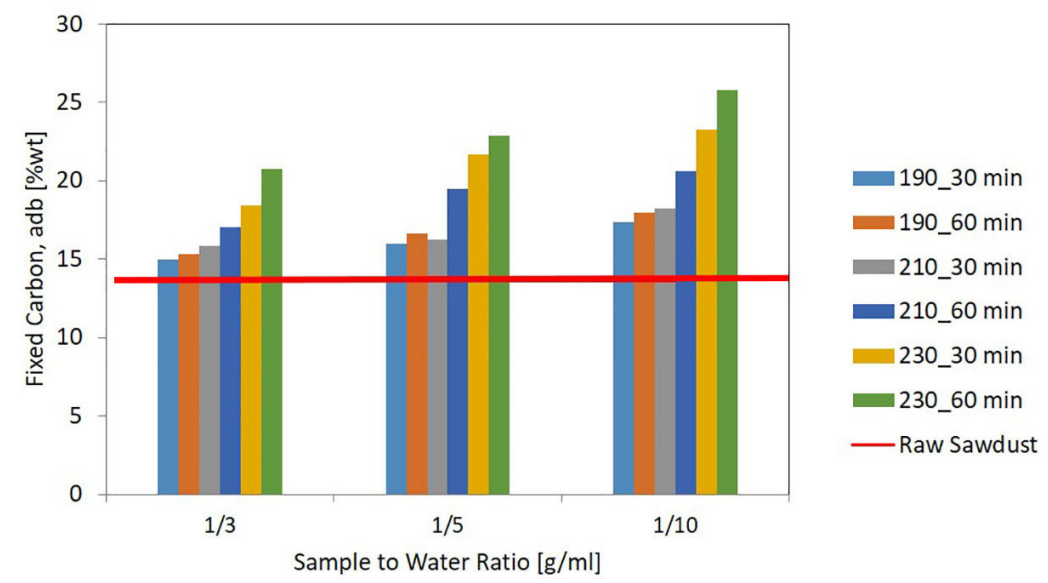

Figure 5. Fixed carbon content of hydrochar

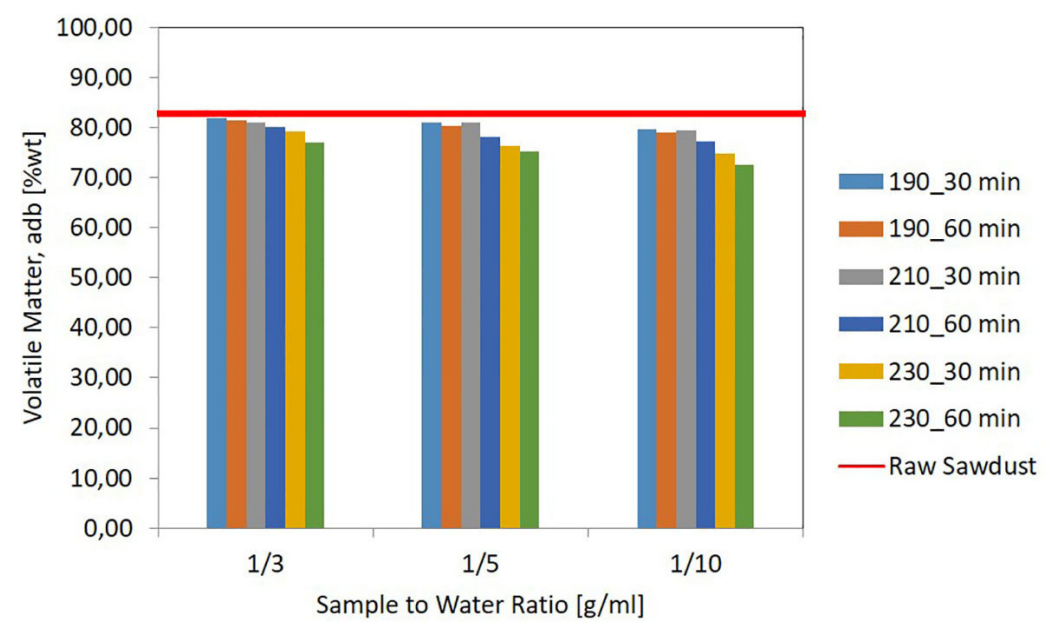

Figure 6. Volatile matter content of hydrochar

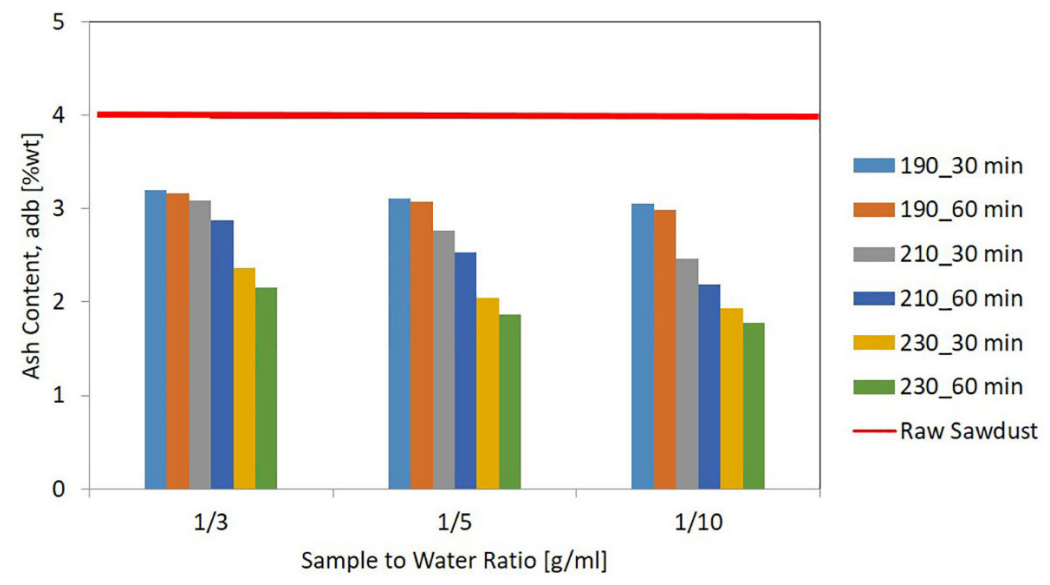

Figure 7. Ash content of hydrochar 


\section{Side products of wet torrefaction of the Albizia sawdust}

The WT process is a thermochemical process consisting of a series of reactions including hydrolysis, dehydration, decarboxylation, and polymerization. The composition analysis of the gas produced by WT sawdust showed that more than $90 \%$ is $\mathrm{CO}_{2}$ gas and a lesser amount is $\mathrm{C} 1-$ C4 gases, with total Net Heating Value of $62-70$ BTU / SCF (Table 3).

Many researchers reported that $3.0-6.1 \%$ of the input carbon is transferred into the gas phase. Due to the aforesaid process of decarboxylation, $\mathrm{CO}_{2}$ is the predominant species detected in the gas phase [Sevilla and Fuertes, 2009; Sevilla et al., 2011; Kruse et al., 2013]. The concentration of $\mathrm{CO}_{2}$ lies around $70-90 \%$, dependent on substrate and reactivity.

From the analysis of the sugar and organic acid content of the resulting liquid product, 5-HMF and furfural are the main components of sugar present in the product, within a range around 2 and $4 \%$ respectively (Table 4). Acetic

Table 3. Composition of HTC gas product

\begin{tabular}{|l|c|}
\hline \multicolumn{1}{|c|}{ Gas product } & \% vol \\
\hline Carbon dioxide & 92.04 \\
\hline Methane & 0.18 \\
\hline Ethane & 0.31 \\
\hline Ethylene & 0.22 \\
\hline Propane & 0.54 \\
\hline Propylene & 1.33 \\
\hline n-Buthane & 0.07 \\
\hline
\end{tabular}

Table 4. The sugar composition

\begin{tabular}{|l|c|}
\hline \multicolumn{1}{|c|}{ Compound } & Percentage* $^{*}$ \\
\hline 5-HMF & 4.6 \\
\hline Furfural & 2.2 \\
\hline Glucose-Pinitol & 0.9 \\
\hline Sucrose-Trehalose & 0.2 \\
\hline Galactose-Xylose-Manose & 0 \\
\hline Fructose-Inositol-Arabinose & 0.1 \\
\hline Arabitol & 0.2 \\
\hline Erythritol & 0 \\
\hline Maltitol & 0.1 \\
\hline Mannitol-Glycerol & 0.06 \\
\hline Levoglucosan & 0.6 \\
\hline
\end{tabular}

Table 5. The organic acid composition

\begin{tabular}{|c|c|}
\hline Compound & Percentage $^{*}$ \\
\hline Acetic Acid & 1.3 \\
\hline Formic Acid & 0.7 \\
\hline Glutaric Acid & - \\
\hline Lactic Acid & 0.5 \\
\hline Maleic Acid & - \\
\hline Malonic Acid & - \\
\hline Oxalic Acid & - \\
\hline
\end{tabular}

and formic acids are organic acids that dominate the solid product with a range of $1-3 \%$ (Table 5).

\section{CONCLUSION}

The study showed that the chemical and physical properties of char varied as a function of the reaction temperature. The results, both in terms of the hydrochar yield and its chemical and thermal properties, showed that wet torrefaction could be an effective way to obtain a solid product with good fuel characteristics. The results showed that as the reaction temperature and holding time increase during the hydrothermal carbonization, the carbon content tends to increase as well. While temperature is increasing, the polarity of molecules is reducing. Thus, the molecules become more easily broken. The results suggested that the wet torrefaction of biomass waste to solid fuel gave the calorific value of $24.55 \mathrm{MJ} / \mathrm{kg}$ after the product dried naturally. Due to the decarboxylation reactions during the process, $\mathrm{CO}_{2}$ was the predominant species detected in the gas phase; the concentration of $\mathrm{CO}_{2}$ lies above $90 \%$. The identified degradation products were sugar and organic acid compounds, which may be desirable feedstocks for the bio-based chemical production.

\section{Acknowledgements}

The authors acknowledge the contributions of Mr Azwar and Mr Asnari from PT. Pertamina RU 3 Plaju. We would like to thank the Research and Development Centre of Mineral and Coal Technology (Tekmira) for the support of this research. This work is financially supported by the Indonesian government through the Ministry of Finance via the Indonesia Endowment Fund for Education (LPDP). 


\section{REFERENCES}

1. Bobleter, O. 1994. Hydrothermal degradation of polymers derived from plants, Prog. Polym. Sci., 19(5), 797-841.

2. Chen, W.H., Kuo, P.C. 2010. A study on torrefaction of various biomass materials and its impact on lignocellulosic structure simulated by a thermogravimetry, Energy, 35, 2580-2586.

3. Chen, W.H., Ye, S.C., Sheen, H.K. 2012. Hydrothermal carbonization of sugarcane bagasse via wet torrefaction in association with microwave heating, Bioresour. Technol., 118, 195-203.

4. Chew, J.J., Doshi, V. 2011. Recent advances in biomass pretreatment-Torrefaction fundamentals and technology, Renew. Sustain. Energy Rev., 15, 4212-4222.

5. Demirbas, A. 2003. Sustainable cofiring of biomass with coal. Energy Convers. Manag. 44, 1465-1479.

6. Demirbas, A. 2005. Potential applications of renewable energy sources, biomass combustion problems in boiler power systems and combustion related environmental issues. Prog. Energy Combust. Sci., 31, 171-192.

7. Eriska, H., Dewi, K., Pasek, A.D., Damanhuri, E. 2017. Hydrothermal carbonization of biomass waste by using a stirred reactor: An initial experimental results, Reaktor, 16(4), 212-217.

8. Funke, A, Ziegler F. 2010. Hydrothermal carbonization of bio- mass: A summary and discussion of chemical mechanisms for process engineering. Biofuels Bioprod. Biorefining-Biofpr 4, 160-177.

9. Heuzé V., Thiollet H., Tran G., Lebas F., 2018. Chinese albizia (Albizia chinensis). Feedipedia, a programme by INRA, CIRAD, AFZ and FAO. https:// www.feedipedia.org/node/336, Accessed on March 20, 2019.

10. Hoekman, S.K., Broch, A., Robbins, C. 2011. Hydrothermal carbonization (HTC) of lignocellulosic biomass, Energy Fuels, 25, 1802-1810.

11. Kruse, A., Damen, N. 2015. Water - A magic solvent for biomass conversion, J Supercrit Fluids, 96, 36-45.

12. Kruse, A., Funke, A., Titirici, M.M. 2013. Hydrothermal conversion of biomass to fuels and energetic materials, Curr. Opin. Chem. Biol., 17, 515-521.

13. Lu, X., Jordan, B., Berge, N.D. 2012. Thermal conversion of municipal solid waste via hydrothermal carbonization: Comparison of carbonization products to products from current waste management techniques, Waste Manag., 32(7), 1353-1365.

14. Martawijaya, A., Sujana, I.K., Mandang, Y.I., Amang., S., Kadir., P.K. 1989. Atlas Kayu Indonesia Jilid II. Badan Penelitian dan Pengembangan Kehutanan.Bogor.

15. Mumme, J., Eckervogt, L., Pielert, J., Diakité, M., Rupp, F., Kern, J. 2011. Hydrothermal carbonization of anaerobically digested maize silage, Bioresour. Technol., 102(19), 9255-9260.

16. Prins, M.J., Ptasinski, K.J., Janssen, F.J.J.G. 2006. More efficient biomass gasification via torrefaction, Energy, 31, 3458-3470.

17. Reza, M.T. 2011. Hydrothermal carbonization of lignocellulosic biomass. MS Thesis, University of Nevada, Reno.

18. Saidur, R., Abdelaziz, E.A., Demirbas, A., Hossain, M.S., Mekhilef, S. 2011. A review on biomass as a fuel for boilers. Renew. Sustain. Energy Rev., 15, 2262-2289.

19. Sevilla, M., Fuertes, A.B. 2009. The production of carbon materials by hydrothermal carbonization of cellulose, Carbon, 47, 2281-2289.

20. Sevilla, M., Maciá-Agulló, J.A., Fuertes, A.B. 2011. Hydrothermal carbonization of biomass as a route for the sequestration of CO2: Chemical and structural properties of the carbonized products, Biomass Bioenergy, 35(7), 3152-3159.

21. Sokhansani, S., Fenton, J. 2006. A BIOCAP: Research integration program, http://www.cesarnet. ca/biocap-archive/rif/report/Sokhansanj_S.pdf. Accessed on 14 Dec. 2017.

22. Yuliansyah, A.T., Hirajima, T., Kumagai, S., Sasaki, K. 2010. Production of solid biofuel from agricultural wastes of the palm oil industry by hydrothermal treatment, Waste Biomass Valoriz., 1, 395-405.

23. Zhang, X., Zhang, L., Li, A. 2017. Hydrothermal co-carbonization of sewage sludge and pinewood sawdust for nutrient-rich hydrochar production: Synergistic effects and products characterization, J. Environ. Manag., 201, 52-62.

24.Zheng, Q., Morimoto, M., Takanohashi, T. 2017. Production of carbonaceous microspheres from wood sawdust by a novel hydrothermal carbonization and extraction method, RSC Adv., 7, 42123-42128. 